\title{
The Effect of Computer-mediated Communication Tools in Online Setting on Iranian EFL Learners' Teaching, Social and Cognitive Existence
}

\author{
Sanam Mehri \\ Department of English Language Teaching, Zanjan Branch, Islamic Azad University, Zanjan, Iran \\ Siros Izadpanah \\ Department of English Language Teaching, Zanjan Branch, Islamic Azad University, Zanjan, Iran
}

\begin{abstract}
This study was conducted to explore the effect of computer-mediated communication tools in online setting on Iranian EFL learners' teaching, social and cognitive existence. The population of the study included 60 English Language Teaching students (B.A) of Zanjan Islamic Azad University using convenient sampling method. Experimental group included half of the participants $(n=30)$ and other half of the participants $(n=30)$ was assigned to control group. As a pretest, participants were asked to fill in the Community of Inquiry (CoI) questionnaire in both experimental and control groups. The learners in the experimental group were taught through electronic mail and chat and the assignments and homework were sent to the learners by E-mail. The teachers asked the learners to answer the questions and send the fulfilled assignments in the telegram group. The learners in the control group were taught conventionally. After the treatment, the questionnaire was readministered among the learners in the both groups as posttest. The learners who received synchronous online communication tools, compared to the respondents who received no treatment, gained higher mean scores on social, teaching and cognitive presence. The findings of the present study can have implications for ESL/EFL contexts from several aspects.
\end{abstract}

Index Terms-cognitive presence, Computer-Mediated Communication (CMC), Community of Inquiry (CoI), social presence, synchronous online communication tools, teaching presence

\section{INTRODUCTION}

Distance learning is a formal means within which the scholar and educator are not within the same place (Parsad \& Lewis, 2008, p. 1). According to Parsad and Lewis (2008), using websites and online learning tools as computermediated communications (CMC) put distance learning in practice. Developments of academic establishments in providing online courses and advances in technologies of personal computer and internet result in growth of online learning literature. Despite all developments and advances, no research has studied the impact of computer-mediated communication (CMC) on teacher education (Mehri \& Izadpanah, 2017). So, it is necessary to examine the relationship between students perception and CMC technology in learning process.

Online learning entails different degrees of Internet-based instruction. Tallent-Runnels, Thomas, Lan, Cooper, Ahern, Shaw, \& Liu (2006) have outlined online courses as those delivered utterly via the web and blending courses as those that mix online components with ancient, face-to-face components (as cited in Salloum, 2011, p.2). Classifying online courses, they are fallen into synchronous or asynchronous (Palloff \& Pratt, 2007). Synchronous learning refers to situations where participants interact in learning tasks at an equivalent time using CMC tools such as group chats in web, video or voice chats, instant text chat. In contrast to synchronous learning, Asynchronous method refers to situations where participants interact in learning activities at separate and freelance times (Salloum, 2011). According to Clark and Mayer (2008), synchronous communication is mainly text-based and employs tools such as e-mail, blogs, wikis, or discussion forums (as cited in Salloum, 2011).

Online learning requires cooperation and interaction activities by nature (Bonk, 2009; Palloff \& Pratt, 2007). CMC allows learners to cooperate with other learners while they share opinions, resources, and information with each other. Through various kinds of CMC tools such as e-mail, news forums, discussion forums, web-conferencing, and text chat, students and instructors communicate with each other (Repman, Zinskie, \& Carlson, 2005; as cited in Salloum, 2011). Teaching or social presence can be promoted by various CMC tools. Finding students perceptions about CMC tool helpfulness is necessary to promote social and teaching presence as well as the influences of tool helpfulness on social and teaching presence. Moreover, it is critical to know the effect of different CMC tools on student perceptions of social, teaching, and cognitive presence. 
In spite of introducing various CMC tools including e-mail, news forums, discussion forums, and web-conferencing into online learning, few studies have attempted to assess student perceptions of their helpfulness for learning (Mehri \& Izadpanah, 2017). Given to the importance of CMC tools in education, online course designers and online course instructors should be provided with necessary information about the fact that which CMC tools are most helpful for students.

It has been seen that CMC tools such as e-mail, news forums, discussion forums, and web-conferencing influence online learning positively; however, research studies should be conducted to explore students perception of mentioned tools (Mehri \& Izadpanah, 2017). This study has attempted to fill the mentioned gap using theoretical basis of Community of Inquiry to investigate the impacts of online CMC tools on the learners' cognitive and social existence.

Therefore, the present study attempted to study EFL learners' attitudes towards online CMC tools effectiveness plus the impact of it on learners' teaching, social and cognitive existence. In fact, social existence assess the develop to which students perceive themselves as real people engaged in communications and interactions with others. Teaching existence assess the develop to which students perceive the instructor's design and facilitation of the learning experience. Cognitive existence assess the develop to which students perceive an ability to construct meaning (Salloum, 2011).

In this study, following questions are investigated:

What are the attitudes of Iranian EFL learners towards online computer-mediated communication tools?

\section{REVIEW OF LITERATURE}

Defining communication, Dale states (1969) that communication is "the sharing of ideas and feelings in a mood of mutuality" (p.10, as cited in Salloum, 2011). Based on Dale`s definition, computer-mediated communication involves activities in which individuals share their opinions and emotions mutualy using CMC tools.

Computer mediated communication can be either synchronous or asynchronous. In synchronous CMC which includes conference by video, chat using text messaging or audio, etc., second language learners can interact with others automatically (or simultaneously). In Asynchronous CMC which includes bulletin boards, electronic cards, e-mail, etc., second language learners have chance of checking and processing messages when they are offline. These are also called real-time communications (Synchronous) and delayed-time (Asynchronous) communications. Regarding CMC tools, Wang (2005) stated,

The internet has overcome problems of distance communicatin by providing different types of communication methods. It means that learnerss can find partners in other language for learning their target language. The internet present some major ways of interaction such audio/video/text chatting, bulletin boards, electronic mails. For example, Yahoo messengers help learners connect with their partners using audio/video chats or send instant messages which are useful for listening and speaking skills improvement.

In an exploratory study, Johnson (2004) investigated theories related to teaching, learning, and teaching design to design a model for online learning and identify factors relating to teacher training education. There were some factors including input and decision options which were measured by continuum scales. Input factors include course goals, instructional intent, nature of content, content structure and complexity, technology resources, and learner characteristics. Decision options include learning objectives, task orientation, teacher role, meta-cognitive goals, and course scheduling and pacing (Salloum, 2011, p.17).

Different types of CMC tools provide different types of media by which learners can communicate and interact with each other. Use and integration of CMC tools can affect attitude of learners toward usefulness of CMC tools in learning process and toward cognitive, social, and teaching existence.

Introducing social existence, Garrison, Anderson and Archer (2001) declared that social existence provides enjoyable and comprehensive group conversatons which supports the learning process. Effective communication requires that learners will be accepted and heard by other group members (Anderson, Rourke, Garrison, \& Archer, 2001). Studying 73 post-baccalaureate teachers with at least one year of teaching experience, Mykota and Duncan (2007) evaluated student perceptions of social presence in four education online courses using a survey instrument developed by Yen and $\mathrm{Tu}$ (2008). As the findings revealed, there was a moderate correlation between previous online courses and student perceptions of CMC proficiency and social presence.

Teaching existence is a process of designing, providing, and directing social and cognitive procedures in order to identify personally significant and academically valuable learning results (Anderson, Garrison, \& Archer, 2001, p. 5). Anderson et al. (2001) attempted to evaluate teaching presence in asynchronous, text-based learning. As the researchers concluded, differences in teaching style, educational philosophy, class size, and familiarity with technology may explain the variations. The researchers also stated that the tool can be used as an identification instrument and a research instrument in order to evaluate teaching existence and investigate factors influencing teaching existence.

Interpreting cognitive existence, Garrison, Anderson and Archer (2001) and Shahlou, and Izadpanah (2016) stated that cognitive existence is the degree of learners` ability to perceive meaning using continuous thinking and discourse by critical query. Garrison et al. (2001) employed a coding instrument to conduct content analysis on transcripts of asynchronous computer conferences. Based on the content analysis results, most indicators reflect the exploration phase of cognitive presence. Lower frequencies of the integration and resolutions phases were attributed to less focus on 
advanced inquiry, lack of instructor facilitation, and effects of the communication medium. It was also suggested that the model of Practical Inquiry might be best suited for applied knowledge learning contexts (as cited in Salloum, 2011, p.49).

Musa, Mohamed, Mufit, Latiff, and Amin (2015) conducted an action research on a project work implemented in Academic Communication Course in Malaysia to investigate the effectiveness of one type of CMC. It was concluded that in addition to the facing challenges, it was very helpful to use CMC during face-to-face interactions to complete the project work. Bataineh and AL-Abdi (2015) explored Computer-Mediated Communication (CMC) effect on EFL learners` sociocultural competence using chat by web-cam. As the research findings revealed, performance of experimental group was better than control group in that experimental group showed more sociocultural factors of language regarding to CMC method of Web-cam chat. As concluded, the experimental group acquired some sociocultural aspects rather than the others. It was also found that the experimental group students have developed their language skills. Rezaee and Ahmadzade (2012) investigated the impact of CMC integration using Face-to-Face interaction in a synchronous and asynchronous method on vocabulary learning of EFL learners. Findings showed that there was no significant improvement in vocabulary scores of the students in the comparison group. However, participants`score in post-test was better than pre-test in both experimental groups. Dehjalali, and Izadpanah, (2017); Mehri, \& Izadpanah, (2017); Niazi and Pourgharib (2013) analyzed the effects of E-mail on improving EFL learners' writing skill and to show the benefits of using one of the new learning opportunities of the age, (e-mail) electronic mail, in an EFL writing class for both students and teachers. For measuring the writing skill, a pre-test and post-test was administered to the learners in the experimental and control groups. The results of the two posttests show improvement of the experimental group.

Therefore, the present project attempts to shed light on the effects of online computer-mediated communication tools on EFL learners' teaching, social and cognitive existence. To this end, the Community of Inquiry as the theoretical framework required to judge student perceptions of the helpfulness of CMC tools was used. In this regard, the following research question was formulated:

Is there any significant difference in students' attitudes toward learning programs with/ without online synchronous meeting (telegram ...) by considering social, cognitive, and teaching existence?

\section{METHOD}

\section{Design}

According to Yin (2003), a research design as a rationale creates relationship between collected data and research questions and results of the study. In this study, quasi-experimental design was used because of randomization impossibility. Students perception and attitude toward CMC and its usefuleness are independent variables and cognitive existence, social existence, and teaching existence are dependent variables.

\section{Participants}

For the purpose of the study, 60 English Language Teaching students (B.A) of Zanjan Islamic Azad University were selected based on convenience sampling method. The students attended in two classes of Listening Comprehension and Speaking 1 course that were held by two different teachers. The statistical population included 70 students. The Cambridge Preliminary English Test (PET) was used to homogenize the participants. In order to select statistical population of the study, subjects $(n=60)$ by scores \pm 1 above and \pm 1 below the standard deviation the were selected. Sampling population was randomly divided into one experimental $(n=30)$ and one control group $(n=30)$.

Instruments

First, the Cambridge Preliminary English Test (PET) was used to homogenize the participants. Then, including email and telegram chat as CMC tools was installed on computers. Another instruments used in the study was the 34item Community of Inquiry (CoI) to assess factors mentioned above. Finally, a scale measuring helpfulness, The 13item Computer mediated communication (CMC) tool, was used.

\section{Procedure}

Tending to investigate the EFL learners ' perceptions of online CMC tools usefulness and impact of tools on learners' cognitive, social and teaching existence, seventy Bachelors of art students of English Language Teaching were selected from Zanjan Islamic Azad University during 2015-2016 schooling year. The students attended in two classes of Listening Comprehension and Speaking 1 course that each class had different teachers. The Cambridge Preliminary English Test (PET) was used to homogenize the participants. In order to select statistical population of the study, subjects $(n=60)$ by scores \pm 1 above and \pm 1 below the standard deviation the were selected. Sampling population was randomly divided into one experimental $(n=30)$ and one control group $(n=30)$. The study was conducted within one semester. The semester included 16 ninety-minute sessions. In order to explore learners` attitude before the treatment, participants were asked to fill in the Community of Inquiry (CoI) questionnaire. The questionnaire was based on Likert Scale (from strongly disagree to strongly agree). The questionnaire was analyzed and the data was drawn to be compared with the result obtained after the treatment. During the study, the experimental group was taught using e-mail and chat. Each session, the teacher taught a unit of the course book "Listening Comprehension and Speaking 1". The task of the course book was then sent to the learners via E-mail. Learners were supposed to do the task and answer the questions and share their assignment in telegram group of the class. In the chat environment, all the students could send 
assignments, voice message and even leave comment on others assignments. Doing so, all the students could participate in class activities and receive their teacher's feedback on their assignments. In other words, CMC tools like e-mail is considered a time-saving method which makes classroom task management easier; on the other side, communication via telegram is interesting, motivating, and enjoyable for learners. In a traditionally handled classroom, it is almost not possible to evaluate all the learners' assignments and involve them in classroom activities. On the contrary, participants of the control group received traditional method of teaching. In the classroom, learners were taught a unit each session. In addition, students discussed about a topic voluntarily of by selection of teacher, answered to the questions, took note of listening activity played in the class, etc. After conducting treatment, the same questionnaire of community of inquiry filled by participants at the start was distributed to the learners in the experimental and control groups. The questionnaires data were drawn and compared with the data obtained on the onset of the study to identify the impact of online CMC tools (e-mail and telegram chat) on the learners' existence of teaching, social and cognitive.

One-Sample Kolmogorov-Smirnov test was used to examine the normal distribution the sample. Results of the test are provided in Table 1 and Table 2 which show distribution of answers to the questionnaire in pre-test and post-test, respectively.

TABLE 1

ONE SAMPLE KOLMOGOROV-SMIRNOV TEST (PRE-TEST)

\begin{tabular}{|c|c|c|c|c|}
\hline & & & pre-test in Control Group & pre-test in Experimental Group \\
\hline $\mathrm{N}$ & & & 30 & 30 \\
\hline Normal & & Mean & 78.5 & 77.5 \\
\hline$\underline{\text { Parameters }}^{\mathrm{a}, \mathrm{b}}$ & & $\mathrm{SD}$ & 1.213 & 1.233 \\
\hline Kolmogorov-Smirnov & $\mathrm{Z}$ & & 367 & .354 \\
\hline Asymp. Sig. (2-led) & & & .216 & .374 \\
\hline
\end{tabular}

TABLE 2

ONE SAMPLE KOLMOGOROV-SMIRNOV TEST (POST-TEST)

\begin{tabular}{|c|c|c|c|}
\hline & & post-test in Control Group & post-test in Experimental Group \\
\hline $\mathrm{N}$ & & 30 & 30 \\
\hline \multicolumn{4}{|l|}{ Normal } \\
\hline & Mean & 78 & 83 \\
\hline \multicolumn{4}{|l|}{ Parameters ${ }^{\mathrm{a}, \mathrm{b}}$} \\
\hline $\begin{array}{l}\text { Kolmogorov- } \\
\text { Smirnov }\end{array}$ & $\mathrm{Z}$ & .411 & .456 \\
\hline $\begin{array}{l}\text { Asymp. Sig. (2- } \\
\text { tailed) }\end{array}$ & & $\begin{array}{l}.123 \\
\text { a. Test distribution is Normal. } \\
\text { b. Calculated from data. }\end{array}$ & .423 \\
\hline
\end{tabular}

Results from Tables 1 and 2, the Kolmogorov-Smirnov indices, confirmed normality of the data at the significant level of $(\mathrm{p}<.05)$. Therefore, it was seen that normality of sample confirmed and research questions can be tested by the parametric tests. So, parametric test are used to investigate the research question. To this end, the learners' responses in both groups were based evaluated on a 5-point Likert scale, where 1= strongly disagree and 5= strongly agree. Then, their scores were determined and the obtained quantitative data was put into statistical analyses. Table 3 demonstrates the descriptive statistics of the two groups in the pretest and posttest for each of teaching present (TP), social present (SP) and cognitive presence (CP).

TABLE 3.

GROUP STATISTICS

\begin{tabular}{|c|c|c|c|c|c|c|c|}
\hline & Groups & $\mathbf{N}$ & & Mean & Standard Deviation & Standard Error Mean & Skewness \\
\hline \multirow[t]{6}{*}{ Pretest } & Experimental & 30 & TP & 1.575 & .342 & .624 & -.154 \\
\hline & & & SP & 1.327 & .311 & .618 & -127 \\
\hline & & & $\mathrm{CP}$ & 1.476 & .334 & .622 & -.135 \\
\hline & Control & 30 & TP & 1.658 & .331 & .605 & -.40 \\
\hline & & & SP & 1.312 & .316 & .619 & -.94 \\
\hline & & & $\mathrm{CP}$ & 1.462 & .342 & .621 & -.111 \\
\hline \multirow[t]{6}{*}{ Posttest } & Experimental & 30 & TP & 3.85 & .213 & .039 & -.908 \\
\hline & & & SP & 3.91 & .209 & .036 & -.595 \\
\hline & & & $\mathrm{CP}$ & 3.73 & .218 & .043 & -.704 \\
\hline & Control & 30 & $\mathrm{TP}$ & 2.68 & .293 & .053 & -.677 \\
\hline & & & SP & 2.65 & .305 & .057 & -.662 \\
\hline & & & $\mathrm{CP}$ & 2.71 & .271 & .066 & -.655 \\
\hline
\end{tabular}

Table 4. signifies the t-test results of the two groups' perceptions mean scores before and after the treatment. 
TABLE 4.

INDEPENDENT SAMPLE T-TEST RESULTS

\begin{tabular}{|c|c|c|c|c|c|c|c|c|c|c|}
\hline & & & \multicolumn{2}{|c|}{ Leven`s Test } & \multicolumn{5}{|c|}{ t-test for Equality of Means } & \multirow[b]{2}{*}{$\begin{array}{l}\text { Standard } \\
\text { Error } \\
\text { Difference }\end{array}$} \\
\hline & & & $\mathbf{F}$ & Sig. & $\mathbf{t}$ & & df & $\begin{array}{l}\text { Sig. (2- } \\
\text { tailed) }\end{array}$ & $\begin{array}{l}\text { Mean } \\
\text { Difference }\end{array}$ & \\
\hline \multirow[t]{3}{*}{ Pretest } & $\mathbf{T P}$ & Equal & .212 & .647 & - & .958 & 58 & .342 & -.08333 & .8696 \\
\hline & $\mathbf{S P}$ & Variances & .207 & .641 & - & .954 & 58 & .342 & -.08259 & .8571 \\
\hline & $\mathbf{C P}$ & Assumed & .210 & .644 & - & .957 & 58 & .342 & -.83012 & .8663 \\
\hline \multirow[t]{3}{*}{ Posttest } & $\mathbf{T P}$ & Equal & 2.035 & .159 & 17.614 & & 58 & .000 & 1.166 & .066 \\
\hline & $\mathbf{S P}$ & Variances & 2.046 & .154 & 17. 627 & & 58 & .000 & 1.199 & .071 \\
\hline & $\mathbf{C P}$ & Assumed & 2.031 & .163 & 17.611 & & 58 & .000 & 1.148 & .63 \\
\hline
\end{tabular}

As Table 4. illustrates, the result of Levene's test, $p=.647$ for TP, $p=.641$ for SP and $p=.644$ for CP signified the equality of the variances and the $t$ observed $(t=0.958, d f=58, p=.342$ for TP; $t=0.954, d f=58, p=.342$ for SP, and $t$ $=0.957, d f=58, p=.342$ for CP) showed no significant difference between the means of the two groups before the treatment. Nevertheless, according to the posttest results, the $t$ observed $(t=17.614, d f=58, p=.000<.05$ for TP; $t=$ 17.627, $d f=58, p=.000<.05$ for SP, and $t=17.611, d f=58, p=.000<.05$ for $\mathrm{CP}$ ) indicates that after using telegram and e-mail for teaching, the experimental group show different perceptions in the items related to TP, SP and CP compared to the control group.

\section{DISCUSSION}

To investigate the research question, the responses of the respondents in the experimental and control groups before and after the treatment were compared. In this regard, the learners' responses in both groups were evaluated based on a 5-point Likert scale, where $1=$ strongly disagree and 5= strongly agree. Then, their scores were determined and the obtained quantitative data was put into statistical analyses. As the independent sample t-test revealed, there was no significant difference between the means of the two groups before the treatment. Nevertheless, according to the posttest results, after using telegram and e-mail for teaching, the experimental group showed different perceptions in the items related to teaching presence, social presence and cognitive presence compared to the control group. The research findings indicated that the participants in the experimental group found the CMC tools (e-mail and telegram) they used in their courses were highly useful for teaching presence (TP), social presence (SP) and cognitive presence (CP) communications. Social presence provides support to the learning process by making group interactions enjoyable and inclusive. Providing the participants with the opportunity to communicate and interact with each other through online tools (in our case, telegram and e-mail) can lead to the increase of their social presence. Therefore, the learners in the experimental group gained higher mean scores after the treatment. Moreover, teaching presence means to what extent instruction of the teacher and learning process is facilitated effectively. As shown in the study, the learners received online communicative tools for teaching perceived greater teaching presence than the learners who received no synchronous tool. Further, cognitive presence refers to the conditions and processes that enable participants in a community of inquiry to build and apply knowledge through a collaborative and constructivist approach to learning (Salloum, 2011, p.130). Receiving instruction through e-mail and applying text-chat on telegram helped the learners to find more collaboration sense, more time for reflection, being more careful, and can think more critically.

As the research findings indicated, e-mail and text-chat on telegram are important CMC tools for promoting teaching presence. They considered e-mail and text-chat on telegram very useful to promote TP communications. The respondents also considered that sending personal messages using e-mail to individuals or to classmates helps develop their social presence. Altogether, using e-mail makes communications with other learners more convenient, private and flexibile.

Consistent with the research findings, Skylar (2009) compared web-conferencing as one type of the online communication tools to asynchronous lecture notes. As he concluded, web-conferencing was very fruitful for the learners' understanding and enabled them to perform better on quizzes. Aria, \& Izadpanah, (2016); Rezaee and Ahmadzade (2012); Izadpanah, \& Alavi( 2016); and Shahrokhi Mehr, Zoghi and Asadi (2013) also reported similar results in other language skills. Unlikely, examining the effect of Synchronous Computer-Mediated Communication (SCMC) on Iranian EFL learners' collaboration, Mozafarianpour and Tahriri (2016) and Chou (2001) reported inconsistent results. The practical significance of this research question was that gender had no significant effect on social, teaching, or cognitive presence of the respondents in the two groups of experimental and control.

\section{CONCLUSION AND IMPLICATIONS}

As found by the data analyses, it was proved that the online communication experience (text chat in telegram and email) can be a positive component that can be integrated into language learning and teaching contexts. In general, the research findings provided useful, practical information for the field of language learning and teaching. The study also provides insights about how the learners' social, teaching and cognitive existences were influenced as a result of receiving synchronous online communicative tools. Social presence is indicators of participants`ability to explain their personal thoughts and feel that they belong to that learning community. Social presence makes learning procedure 
interesting and involving by supporting learning process. One of the key issues in social presence is that learners feel themselves accepted and heard by other group memebers in order to involve in an effective communication (Salloum, 2011). As found, the mean differences among the two groups for social presence were statistically significant. In other words, using CMC tools can promote social presence. Providing the participants with the opportunity to communicate and interact with each other through online tools (in our case, telegram and e-mail) can lead to the increase of their social presence. Teaching presence includes effective designing and facilitation of learning procedures which instructor provides in classroom. As shown in the study, the learners received online communicative tools for teaching perceived greater teaching presence than the learners who received no synchronous tool. Using different types of CMC tools by teachers for various purposes might be considered a criterion to evaluate teaching presence perceptions (Salloum, 2011). Because online communication tools and here, telegram and e-mail require careful design, invite participation, and require instructor facilitation, the learners perceived greater teaching presence through these tools. Regarding cognitive presence, it can be said that it is capability of participants in creation of meaning via discussion and interaction activities. In other words, cognitive presence provides situations in which learners can collaboratively use information and build knowledge using discussions and inquiries. In the study, the learners in the experimental group also gained higher score in cognitive presence section, indicating the effect of synchronous online communicative tools can stimulate superior reflection and thoughts in order (Repman et al., 2005, as cited in Salloum, 2011). Furthermore, it has been stated that asynchronous discussion forums provide time for reflection, tend to be complex and explicit, and are associated with careful, critical thinking (Garrison, Anderson, \& Archer, 2000, as cited in Salloum, 2011).

It can be implied from the results that online communicative tools such as text-chat on telegram and e-mail motivate learners to interact with the topics and play a key role in helping learners incorporate constructs, use information in various contexts, and find solutions for problems. As another implication of the study, it should be noted that teachers, curriculum designers, and instructors should study the ways for integration of CMC tools such as e-mail and discussion forums in order to influence cognitive, social, and teaching existence positively. Larger populations can be studied to determine possible differences in student perceptions about CMC tool helpfulness and relationships with social, teaching and cognitive presences. Future studies can examine which tools are most helpful for different communications and purposes. The effect of different combinations of CMC tools on learners' perceptions of social, teaching, and cognitive presence can be also explored by other researchers.

\section{APPENDIX A}

The Cambridge Preliminary English Test (PET)

http://cambridgeesol.org/exams/general-english/pet.html

\section{APPENDIX B}

The survey instrument consists of three parts: Community of Inquiry items, communication mode items, and demographics. The instrument employs a five point Likert scale as follows:

$1=$ strongly disagree; $2=$ disagree; $3=$ undecided; $4=$ agree $; 5=$ strongly agree

Community of Inquiry Items

$\sqrt{ }$ Teaching presence.

$\sqrt{ }$ Design and organization.

1. The instructor clearly communicates important course topics.

2. The instructor clearly communicates important course goals.

3. The instructor provides clear instructions on how to participate in course learning activities.

4. The instructor clearly communicates important due dates/time frames for learning activities.

$\sqrt{ }$ Facilitation.

5. The instructor is helpful in identifying areas of agreement and disagreement on course topics that helped me to learn.

6. The instructor is helpful in guiding the class towards understanding course topics in a way that helped me clarify my thinking.

7. The instructor helps to keep course participants engaged and participating in productive dialogue.

8. The instructor helps keep the course participants on task in a way that helped me to learn.

9. The instructor encourages course participants to explore new concepts in this course.

10. Instructor actions reinforce the development of a sense of community among course participants.

$\sqrt{ }$ Direct instruction.

11. The instructor helps to focus discussion on relevant issues in a way that helped me to learn.

12. The instructor provides feedback that helped me understand my strengths and weaknesses.

13. The instructor provides feedback in a timely fashion.

$\sqrt{ }$ Social presence.

$\sqrt{ }$ Affective expression.

14. Getting to know other course participants give me a sense of belonging in the course. 
15. I is able to form distinct impressions of some course participants.

16. Online or web-based communication is an excellent medium for social interaction.

$\sqrt{ }$ Open communication.

17. I feel comfortable conversing through the online medium.

18. I feel comfortable participating in the course discussions.

19. I feel comfortable interacting with other course participants.

$\sqrt{ }$ Group cohesion.

20. I feel comfortable disagreeing with other course participants while still maintaining a sense of trust.

21. I feel that my point of view is acknowledged by other course participants.

22. Online discussions help me to develop a sense of collaboration.

$\sqrt{ }$ Cognitive presence.

$\sqrt{ }$ Triggering event.

23. Problems pose increased my interest in course issues.

24 . Course activities pique my curiosity.

25. I feel motivated to explore content related questions.

$\sqrt{ }$ Exploration.

26. I utilize a variety of information sources to explore problems posed in this course.

27. Brainstorming and finding relevant information help me resolve content related questions.

28. Online discussions are valuable in helping me appreciate different perspectives.

$\sqrt{ }$ Integration.

29. Combining new information help me answer questions raised in course activities.

30. Learning activities help me construct explanations/solutions.

31. Reflection on course content and discussions help me understand fundamental concepts in this class.

$\sqrt{ }$ Resolution.

32. I can describe ways to test and apply the knowledge created in this course.

33. I have developed solutions to course problems that can be applied in practice.

34. I can apply the knowledge created in this course to my work or other non-class related activities.

CMC Tool Helpfulness Items

Participants are asked to rate their level of agreement with the following statements about the CMC tools they used in their online courses. The same five -point Likert scale is used with an additional option of .did not use. Because not all tools are utilized by all participants.

$\sqrt{ }$ Helpfulness for teaching presence items.

35. Using e-mail and text chat is helpful for receiving information from my instructor about course topics, goals and learning activities.

36. Using e-mail and text chat is for receiving directions or clarification from my instructor.

37. Using e-mail and text chat is helpful for receiving personal feedback from my instructor.

38. Using e-mail and text chat is helpful for communicating questions or concerns to my instructor.

$\sqrt{ }$ Helpfulness for social presence items.

39. Using e-mail and text chat is helpful for getting to know other course participants.

40. Using e-mail and text chat is helpful for interacting and collaborating with other course participants.

$\sqrt{ }$ Comfort level.

41. I am comfortable using e-mail and text chat.

Demographic Items

42. What is your gender?

. Male

. Female

43. Prior to the current semester, how many online courses have you taken?

. None

. One

. Two

. Three

. Four or more

44. How many years of teaching experience do you have?

\author{
Years of teaching experience \\ None \\ 1 year or less \\ 1 to 2 years \\ 2 to 3 years \\ More than 3 years
}




\section{REFERENCES}

[1] Anderson, T., Rourke, L., Garrison, D. R., \& Archer, W. (2001). Assessing teaching presence in a computer conferencing context. Journal of Asynchronous Learning Networks, 5(2). Retrieved December 10, 2004, from http://www.aln.org/publications/jaln/v5n2/.

[2] Aria, M. R., \& Izadpanah, S. (2016). The impact of weblog on performance of Iranian Intermediate EFL learners in EFL writing.2(3) 23-43.

[3] Bataineh, A. M., \& Al-Abdali, A. I. (2015). The Effect of Using Web-Cam Chat on the Undergraduate EFL Learners' SocioCultural Competence. International Journal of Education, 7(2), 242-267.

[4] Bonk, C. (2009). The world is open: How web technology is revolutionizing education. San Francisco: Jossey-Bass.

[5] Clark, R. C., \& Mayer, R. E. (2003). E-learning and the science of instruction: Proven guidelines for consumers and designers of multimedia learning. San Francisco: Jossey-Bass/Pfeiffer.

[6] Dale, E. (1969). Audiovisual methods in teaching (3rd ed.). New York: The Dryden Press.

[7] Dehjalali, M. R., \& Izadpanah, S. (2017). The Study of Vocabulary Awareness Effect on Intermediate Language Learners' Depth of Vocabulary Knowledge in Genuine Persian Texts. International Journal of English Linguistics, 7(1), 185-192.

[8] Garrison, D. R., Anderson, T., \& Archer, W. (2001). Critical thinking, cognitive presence, and computer conferencing in distance education. American Journal of Distance Education, 15(1), 7-23.

[9] Izadpanah, S., \& Alavi, M. (2016). The Perception of EFL High School Students in Using of Computer Technology in the Process of Learning: Merits and Demerits. Advances in Language and Literary Studies, 7(3), 146-156.

[10] Mehr, H. S., Zoghi, M., \& Assadi, N. (2013). Effects of Synchronous Computer-Mediated Communication and Face-to-Face Interaction on Speaking Skill Development of Iranian EFL Learners. International Journal of Applied Linguistics and English Literature, 2(5), 36-41.

[11] Mehri, S., \& Izadpanah, S. (2017). A Qualitative Study of the Perceptions of Iranian EFL Learners' Attitudes towards CMC Tools Usefulness. Theory and Practice in Language Studies, 7(8), 682-689.

[12] Mozafarian Pour, A., \& Tahriri, A. (2016). Impact of Synchronous Computer-Mediated Communication on EFL Learners' Collaboration: A Quantitative Analysis. Journal of Teaching Language Skills, 4(2), 115-140.

[13] Musa, F., Mohamed, M., Mufti, N., Latiff, R. A., \& Amin, M. M. (2015). Incorporating computer-mediated communication in project work. International Education Studies, 8(5), 150-158.

[14] Mykota, D. \& Duncan, R. (2007). Learner characteristics as predictors of online social presence. Canadian Journal of Education, 30(1), 157-170.

[15] Niazi, F., \& Pourgharib, B. (2013). The effect of virtual language learning method on writing ability of Iranian intermediate EFL learners. International Research Journal of Applied and Basic Sciences, 4 (11), 331-339.

[16] Palloff, R. M., \& Pratt, K. (2007). Building online learning communities: Effective strategies for the virtual classroom. John Wiley \& Sons. San Francisco.

[17] Parsad, B. \& Lewis, L. (2008). Distance education at degree-granting postsecondary institutions: 2006-1007 (NCES 2009-044). Washington DC: National Center for Education Statistics, Institute of Education Sciences, U.S. Department of Education.

[18] Repman, J., Zinskie, C., \& Carlson, R. (2005). Effective use of CMC tools in interactive online learning. Computers in the Schools, 22(1), 57-69.

[19] Rezaee, A. A., \& Ahmadzadeh, S. (2012). Integrating Computer Mediated with Face-to-face Communication and EFL Learners" Vocabulary Improvement. Journal of Language Teaching and Research, 3(3), 346-352.

[20] Salloum, S. R. (2011). Student perceptions of computer-mediated communication tools in online learning: Helpfulness and effects on teaching, social, and cognitive presence (Doctoral dissertation, The University of North Carolina at Charlotte).

[21] Shahlou, P., \& Izadpanah, S. (2016). The Study of Relationship Between EFL Teacher's Teaching Context and Their Attitudes Towards Computer Assisted Language Learning. The Social Sciences, 11(29), 7018-7024.

[22] Skylar, A. A. (2009). A comparison of asynchronous online text-based lectures and synchronous interactive web conferencing lectures. Issues in Teacher education, 18(2), 69-79.

[23] Tallent-Runnels, M. K., Thomas, J. A., Lan, W. Y., Cooper, S., Ahern, T. C., Shaw, S. M., \& Liu, Xiaoming. (2006). Teaching courses online: A review of the research. Review of Educational Research, 76, 93-135.

[24] Wang, L. (2005). The advantages of using technology in second language education. T.H.E. Journal, 32(10), 1-6.

[25] Yin, R.K. (2003). Case study research: Design and methods, 3rd ed. edn. Sage, Thousand Oaks. San Francisco.

Sanam Mehri was born in Zanjan, Iran, in 1989. She received M.A. degree in Teaching English as a Foreign Language (TEFL) from Islamic Azad University of Zanjan, in 2017. She has taught English in Zanjan private language institutions. Her professional interests are teaching English and second language acquisition.

Siros Izadpanah received Ph.D. in Teaching English as a Foreign Language (TEFL). He has been teaching in Azad University of Zanjan for 15 years. He has compiled seven books for university students and published many articles in international journals and conferences. 